\title{
OBITUARY
}

\section{Hubert JoHN GiBSON, 1904-1967}

Hubert Gibson, who died on June 6, 1967, qualified in Edinburgh in 1926 and took his D.P.H. in 1929 and his M.D. in 1935 . He came to Bath in 1934, and made the laboratory of the Royal National Hospital for Rheumatic Diseases his base, even after he became senior pathologist to the Hospital Group Laboratory at the Manor.

During the second world war, when most physicians were away, he showed his great knowledge of general medicine and was able to advise practitioners on both diagnosis and treatment as well as carrying out pathological examinations for them.

He was much sought after on all important committees because of his sound commonsense and balanced judgement. Because of this, his integrity and his humanity, his opinion was valued perhaps more than anyone's on difficult problems, medical administration, and even on houses and motor-cars.

In spite of his many interests, rheumatology always took priority. It is doubtful whether there was a pathologist in the country with a wider knowledge of this subject. Amongst his many literary contributions he wrote the Section on
Pathology for Copeman's "Text-book on the Rheumatic Diseases".

He was a great rheumatologist and a wonderful friend, who will be sorely missed in Bath, and especially at the Royal National Hospital.

\section{TOMMASO LUCHERINI, 1891-1967}

With great regret we announce the death on May 23, 1967, of Prof. Tommaso Lucherini, who was well known to all as a leader of Italian rheumatology, which he represented as a Councillor on the European League against Rheumatism.

He was decorated for his service in the Italian army medical corps in the first world war and had a distinguished career in medicine at the University of Rome, where he held various important hospital appointments.

He was past president of the Società Italiana di Reumatologia, founder of the "Giornate Rheumatologiche Romane", and a member of the editorial board of the periodical Reumatismo. He published numerous scientific articles and also wrote several authoritative text-books on rheumatism.

\section{SOUTH EAST ASIA AND PACIFIC AREA LEAGUE AGAINST RHEUMATISM}

\author{
I Congress, Bombay, February 17 to 21, 1968
}

The organizers are particularly anxious that rheumatologists from the United Kingdom should participate in this first Seapal Congress, which will be attended by specialists from all over the world. Particulars may be obtained from the Secretary-General:

Dr. M. M. Desai,

Fateh Manzil, 457-59 Lamington Road, Bombay 4. 